\title{
Bovine Viral Diarrhea Milk ELISA Test Detecting Anti-p80 Antibody - Association with Milk Handling Methods and Cow Characteristics
}

\author{
David J. Wilson*, Kerry A. Rood and Gregory M. Goodell
}

Department of Animal, Dairy, and Veterinary Sciences, Utah State University, Logan, UT 84341 (Wilson, Rood), The Dairy Authority, Greeley, CO 80634 (Goodell), USA

\begin{abstract}
A milk ELISA test for Antibody (Ab) against Bovine Viral Diarrhea (BVD) virus was studied in a dairy herd with past diagnoses of calves dying from BVD and Persistently Infected (PI) cows, with culling of all known PI cows. Modified live BVD vaccine was administered to calves 3 months and 4 months old, all cows at dryoff 45 to 60 days before calving, and 15-21 days in milk (DIM). Cows were tested 1 month apart (247 and 258 cows, respectively) using a competitive ELISA for milk Ab binding to $\mathrm{p} 80 \mathrm{BVD}$ non-structural protein. Results are reported as $\%$ binding by a second $\mathrm{Ab}$; higher second $\mathrm{Ab}$ binding means the milk had less anti-p80 BVD Ab. Cows with $90-100 \%$ binding in milk on both tests were classified as low Ab-interpreted as a cow with PI or vaccine failure. Milk handling method was significant; fresh milk mean $49 \%$ second $\mathrm{Ab}$ binding was higher than for milk preserved 3 other ways. In fresh milk, 15 cows had $90-98 \%$ binding on one test, but $14 / 15$ were milking during both herd tests and were below $90 \%$ on the other tests. Stage of lactation significantly affected results; anti-BVD Ab was higher from 1-30 DIM and lower from 61-150 DIM than at other stages of lactation. Ear notches were sampled concurrently from all cows for BVD antigen capture ELISA testing. Neither the milk ELISA results (no cows $>90 \%$ second Ab binding on both milk tests) nor ear notch testing classified any cows as PI animals. The milk BVD test might be useful to the dairy industry as a practical and convenient test for screening herd replacements, especially when large numbers of lactating cows are purchased and mixed into different pens throughout a dairy herd.
\end{abstract}

Keywords: Antibody; Bovine Viral Diarrhea; ELISA; Milk

\section{Introduction}

Bovine Viral Diarrhea (BVD), caused by BVD virus, a pestivirus, is an important respiratory, gastrointestinal, ocular, and reproductive tract disease complex of dairy cattle [1-3]. Calves infected with BVD in utero may be aborted, born malformed, or born apparently normal, and like calves infected as neonates, may contract diarrhea, respiratory disease, or neurologic signs $[1,2,4,5]$. Calves infected from 60 to 120 days of gestation may become Persistently Infected (PI) animals [2,4]. Such PI animals are a small percentage of the dairy cattle population, often clinically normal, may survive to adulthood, shed large amounts of BVD virus from bodily secretions throughout their lives, and are the major source of infections in herdmates resulting in clinical disease, abortions, and production losses $[2,6]$.

Because they are of low prevalence and high importance, detection and removal of all PI animals from dairy herds is the single most effective BVD control measure known to date [2,7]. Many different tests for BVD using blood, milk (including bulk tank milk for initial herd screening) or tissues as the sample are available, and numerous test strategies are used around the world. Tests include indirect or competitive ELISAs, virus isolation from inoculated bovine cell cultures, and viral antigen detection ELISAs [7]. Viral antigen capture ELISA tests have become most popular in the U.S., with skin biopsy in the form of ear notches being the sample most commonly tested $[7,8]$.

The study reported here evaluated a milk test for BVD commercially available in the European Union (Idexx, Montpellier, France). The test is a competitive (blocking) ELISA for detection of milk antibody (Ab) specific for "BVD p80 Antigen", p80/125 non-structural protein, also sometimes called non-structural protein 3, common to all strains of BVD virus. The principal objectives were to evaluate potential association of different milk sample handling methods or cow characteristics such as age and stage of lactation with milk ELISA results, determine repeatability of consecutive monthly test results, and test for possible association of anti-BVD Ab with milk production adjusting for other significant factors.

\section{Materials and Methods}

\section{Study herd}

A commercial dairy farm in Utah milking approximately 250 cows, primarily Holsteins but some Jerseys, participated in the study. During the previous 2 years, 3 calves approximately 3 days old (2 Jerseys, 1 Holstein) that died and for which BVD was diagnosed as the main cause of death and 2 PI Holstein cows diagnosed by antigen capture ear notch ELISA (Idexx, Westbrook, ME) were detected in the herd by testing at the Utah Veterinary Diagnostic Laboratory (UVDL). The farm had an established practice of culling PI cows; in accordance the 2 cows detected as PI were culled before the study. Modified live BVD vaccine was administered to 3 and 4 month old calves, 45 to 60 days before expected date of calving (this was at time of dry off in cows expecting their $2^{\text {nd }}$ or greater calf), and 15-21 DIM following calving.

\section{Tests and testing schedule}

All lactating cows were tested at consecutive monthly Dairy Herd Improvement Association (DHIA) herd tests (35 days apart). Milk

*Corresponding author: David J. Wilson, Department of Animal, Dairy, and Veterinary Sciences, Utah State University, Utah Veterinary Diagnostic Laboratory, 950 East 1400 North, Logan, UT 84341, USA, Tel: (435) 760-3731; Fax: (435) 797 2805; E-mail: David.Wilson@usu.edu

Received March 24, 2012; Accepted May 17, 2012; Published May 22, 2012

Citation: Wilson DJ, Rood KA, Goodell GM (2012) Bovine Viral Diarrhea Milk ELISA Test Detecting Anti-p80 Antibody - Association with Milk Handling Methods and Cow Characteristics. J Veterinar Sci Technol 3:114. doi:10.4172/21577579.1000114

Copyright: ( 2012 Wilson DJ, et al. This is an open-access article distributed under the terms of the Creative Commons Attribution License, which permits unrestricted use, distribution, and reproduction in any medium, provided the original author and source are credited. 
Citation: Wilson DJ, Rood KA, Goodell GM (2012) Bovine Viral Diarrhea Milk ELISA Test Detecting Anti-p80 Antibody - Association with Milk Handling Methods and Cow Characteristics. J Veterinar Sci Technol 3:114. doi:10.4172/2157-7579.1000114

samples were collected using DHIA milk meters, and samples were chilled and transported in coolers to the UVDL. Samples were shipped in insulated containers with frozen gel cold packs overnight by courier to The Dairy Authority (TDA) Laboratory in Greeley, CO. At TDA, samples were aliquoted and handled in one of 4 ways: fresh milk (tested the day after collection), no 2-Bromo-2-nitro-1,3-propanediol (Bronopol, D \& F Control Systems, San Ramon, CA) preservative pill; 2 days post-collection milk, preservative pill; milk frozen for 7 days post-collection, no preservative pill; milk at room temperature for 7 days post-collection, preservative pill. Production and lactation data on all milking cows was recorded electronically by DHIA, and the information was transmitted to the investigators.

All adult cows including pre-calving heifers nearing their first calving were tested for BVD using antigen capture ELISA on ear notch tissue during the month of the study, between the 2 DHIA visits. Individual-cow ear notch tissue samples were collected, placed in sealed and labeled vials, and shipped the same day via overnight courier to AgSource Laboratories in Jerome, ID for antigen capture ELISA testing (Idexx, Westbrook, ME) performed as described previously [9].

\section{BVD milk ELISA}

The non-structural protein $\mathrm{p} 80 / 125$ (p80), an antigen common to all strains of BVD virus, was coated onto the walls of 96-well polystyrene microplates included in the test kit. Milk samples (100 $\mu \mathrm{l})$ were added to each test well and the plate was covered with an adhesive plate sealer and incubated for $2 \mathrm{hr}$ at $21^{\circ} \mathrm{C}$. If present, anti-p80 $\mathrm{Ab}$ in the milk bound to the p80 BVD antigen in the wells during the incubation period. Contents of plates were then emptied. Plates were washed 3 times (wells filled with $300 \mu \mathrm{l}$ of test kit wash solution using an automated plate washer). The first wash remained in the wells for 3 minutes, the last 2 washes were emptied immediately, and after the final wash the inverted plates were struck firmly on a towel on a counter top. Anti-p80 Ab WB112 coupled to peroxidase $(100 \mu \mathrm{l})$ was added to each well and the plate was covered with an adhesive plate sealer and incubated for $30 \mathrm{~min}$ at $21^{\circ} \mathrm{C}$. The more anti-p 80 (anti-BVD) $\mathrm{Ab}$ that was present in a milk sample, proportionally less of the second test kit anti-p80 Ab WB112 could bind to the well during the incubation period. After plates were emptied and washed 3 times as above, 100 $\mu \mathrm{l}$ of the enzyme substrate $3,3^{\prime}, 5,5^{\prime}$ - Tetramethylbenzidine (TMB) was added to the wells and incubated for $20 \mathrm{~min}$ at $21^{\circ} \mathrm{C}$ away from light. Then $100 \mu \mathrm{l}$ of $\mathrm{H}_{2} \mathrm{SO}_{4} 0.5 \mathrm{M}$ stock solution was added to each well and plates were gently shaken on a plate shaker until the colored solution was visibly homogenized. The TMB only binds to the second peroxidase-coupled $\mathrm{Ab}$, producing a color change (blue to yellow). The intensity of the color change was read by an ELISA photometric plate reader at $450 \mathrm{~nm}$ (blanked on air) and was an inverse measure of the level of anti-p80 (anti-BVD) Ab present in the milk samples.

One positive control serum and 2 negative control sera (test kit reagents) were included on each 96-well plate. The positive control demonstrated reduced binding by the test kit anti-p80 Ab WB112 (must be no more than $20 \%$ of the mean binding of the negative control samples). The mean of the negative controls provided a reference level for $100 \%$ binding by the test kit anti-p $80 \mathrm{Ab} \mathrm{WB1} 12$ and a corresponding $\mathrm{OD}$ (must have minimum $\mathrm{OD}_{450}$ of 0.8 ). The lower the $\mathrm{OD}$ of a well that was used to test a milk sample, the more anti-BVD Ab was present in that sample. Results are expressed as \% binding by the second test kit $\mathrm{Ab}(\mathrm{BVD} \%)$ as measured by the OD of each sample well in proportion to the mean OD of the 2 negative control wells. Interpretation of the BVD\% binding is as follows: $90-100 \%$, low anti-BVD Ab in cow's milk
- possible PI or vaccine failure; $60-89 \%$, moderately low anti-BVD Ab; 30-59\%, moderate anti-BVD Ab; 10-29\%, high anti-BVD Ab; 0-9\%, very high anti-BVD Ab in cow's milk.

\section{Statistical Analysis}

Systat 13 was used for statistical testing. Descriptive statistics, tests for normality and type of distribution of variables, and analysis of residuals were performed. Analysis of variance (ANOVA), and if significant differences were indicated, Tukey's multiple comparison test for differences in means of continuous variables among categorical variables (groups) were used. Correlation between 2 continuous variables was performed. General linear models (GLM) were used to evaluate the association of potential explanatory variables with a continuous outcome variable of interest such as milk production. Logical potential explanatory variables and possible interactions were tested and only significant variables were included in the final model. Level of statistical significance used was $\alpha=0.05$.

\section{Results}

During the 2 consecutive monthly DHIA herd visits, 247 and 258 cows were milk sampled. There were 226 cows that were milking on both test days and were sampled twice.

Negative controls (reference level for $100 \%$ binding by the test kit anti-BVD Ab; must have minimum OD of 0.8) had mean OD of 1.73 (range $1.36-2.10$ ). Positive controls (must have mean BVD\% [binding] no more than 20\%) had mean OD of 0.08 (range $0.07-0.10$ ), with mean BVD $\%$ of $4.8 \%$ (range $4.1 \%$ - 5.2\%). BVD\% differed among the 4 milk handling methods $(\mathrm{P}<0.001$, ANOVA), however the only significant difference was between the 2 milk handling methods with the highest and lowest BVD\%, fresh milk and room temperature for 7 days with preservative pill, respectively (Tukey's, $\mathrm{P}<0.01$ ). Means for $\mathrm{BVD} \%$ were as follows (means with the same superscript letter are not significantly different from each other): fresh milk, no preservative pill $49 \%^{\mathrm{a}}$; 2 day old milk with preservative pill $45 \%^{\mathrm{ab}}$; sample frozen for 7 days, no preservative pill $45 \%{ }^{\text {ab }}$; sample at room temperature for 7 days with preservative pill $42 \%$ bc . Also, no cows with $>90 \%$ BVD $\%$ (low antiBVD Ab) cows were detected with any sample type except fresh milk with no preservative.

Correlation between BVD\% values for the same cows using different milk sampling methods was determined for each combination of 2 handling methods ( $\mathrm{n}=505$ cows) and also for the 2 monthly test values for the 226 cows tested twice. Correlation of BVD\% between any 2 milk sample handling methods or consecutive DHIA tests using the same method was always approximately $r=0.65$. The pattern was always observed that for low BVD\% cows (high $\mathrm{Ab}$ ), there was a stronger relationship between differently handled milk samples than for high BVD\% cows (low Ab) (Figure 1 and Figure 2).

The remaining results are shown for fresh milk with no preservative only. The BVD\% ranges for the 2 months were 3-98\% and $4-96 \%$. Quartiles were $29 \%, 47 \%, 62 \% 1^{\text {st }} \mathrm{mo}, 35 \%, 56 \%, 71 \% 2^{\text {nd }}$ mo; the distribution of BVD\% values was approximately normal (Figure 3 and Figure 4).

There were 15 cows with $90-98 \%$ BVD\%, in the range that is interpreted that they are possibly PI cows or vaccine failures: 4 cows during the first month (96-98\% BVD\%) and 11 cows during the second month (90 - 96\% BVD\%). This represents 5.3\% (15/279) of all cows tested at least once, and 3.0\% (15/505) of all BVD tests during the 2 mo. However, 14 of those 15 cows were tested during both months (all 
Citation: Wilson DJ, Rood KA, Goodell GM (2012) Bovine Viral Diarrhea Milk ELISA Test Detecting Anti-p80 Antibody - Association with Milk Handling Methods and Cow Characteristics. J Veterinar Sci Technol 3:114. doi:10.4172/2157-7579.1000114

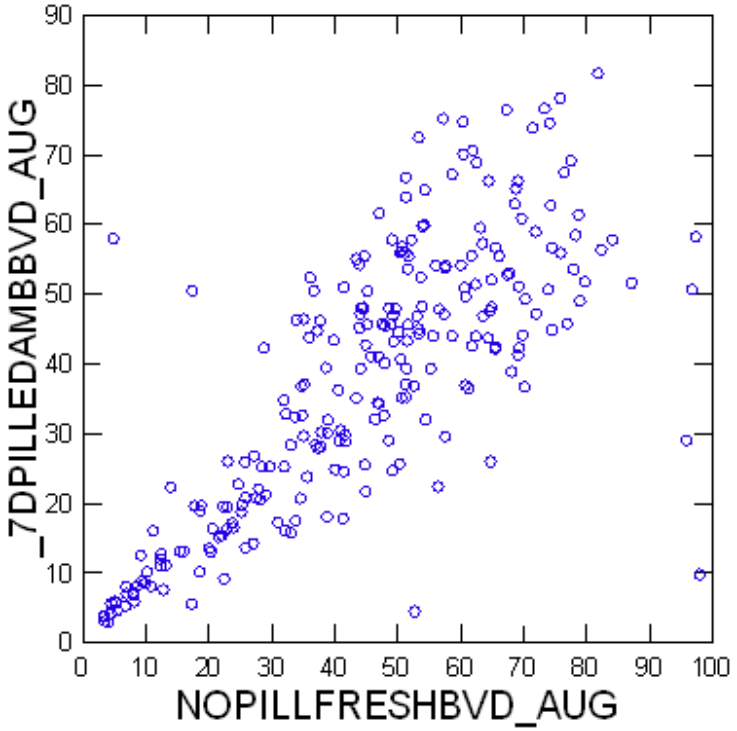

Figure 1: Values of milk anti-p80 BVD Ab binding \% from fresh milk with no Bronopol preservative pill (x-axis) compared to milk stored at room temperature for 7 days with preservative pill (y-axis) from the same cows. Correlation between combinations of 2 sample handling methods (there were 4 different sample handling methods) was always close to $r=0.65$, the correlation shown here. The pattern was always evident that for low BVD Ab binding $\%$ values (higher anti-p80 BVD Ab in milk), there was a stronger relationship between differently handled milk samples than for high BVD Ab binding $\%$ values (lower anti-p80 BVD Ab in milk) as shown in the upper right corner.

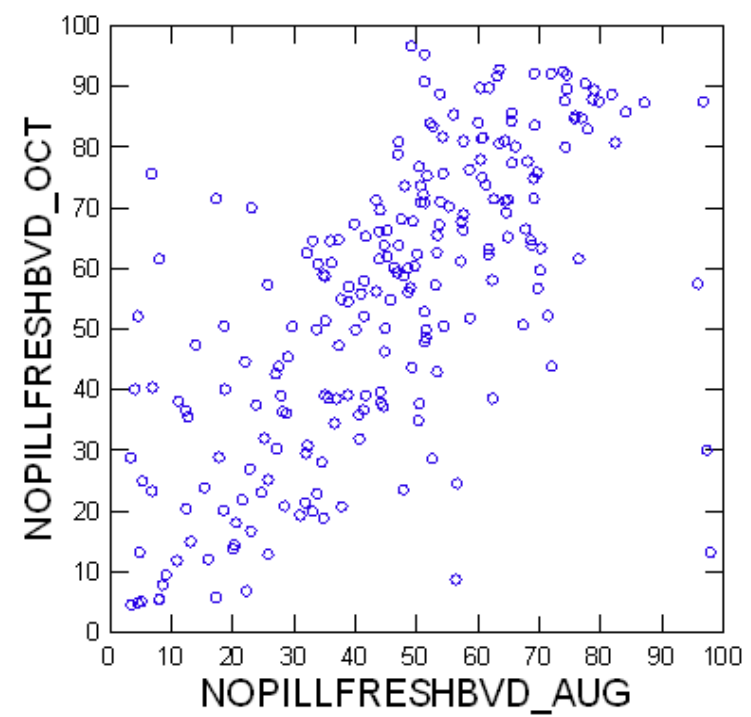

Figure 2: Values of milk anti-p80 BVD Ab binding \% from fresh milk samples with no Bronopol preservative pill collected at consecutive DHIA tests 35 days apart from the same cows. Correlation was $r=0.68$ between the 2 months.

4 cows $>90 \%$ BVD\% the first month were retested the second month, $10 / 11$ cows $>90 \%$ the second month had been tested the month before) and none were $>90 \%$ BVD\% both times. During the month other than when they were $>90 \%$, their BVD\% ranged from $18 \%$ to $77 \%$, with most less than $55 \%$, except for one cow whose BVD\% was $97 \%$, then $87 \%$. At the time of the second test, the latter cow was 118 DIM, her daily

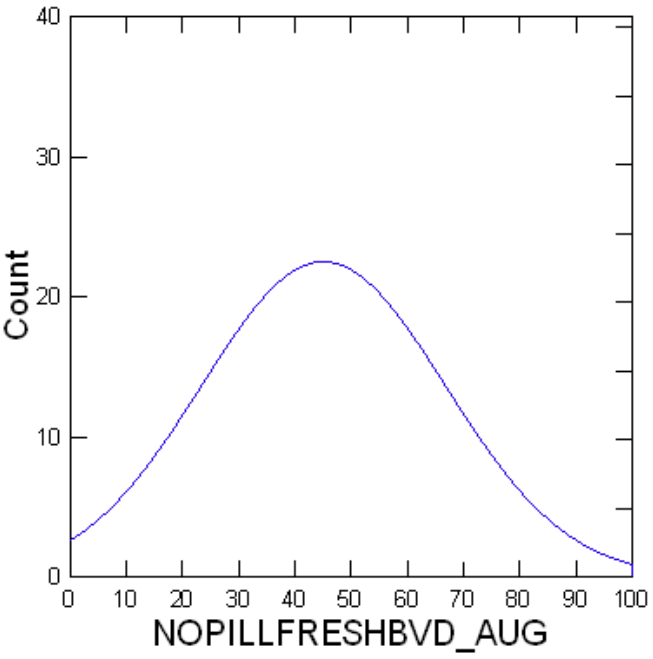

Figure 3: Values of milk anti-p80 BVD Ab binding \% were approximately normally distributed. Values shown are for August $A b$ binding $\%$ in fresh milk with no Bronopol preservative pill.

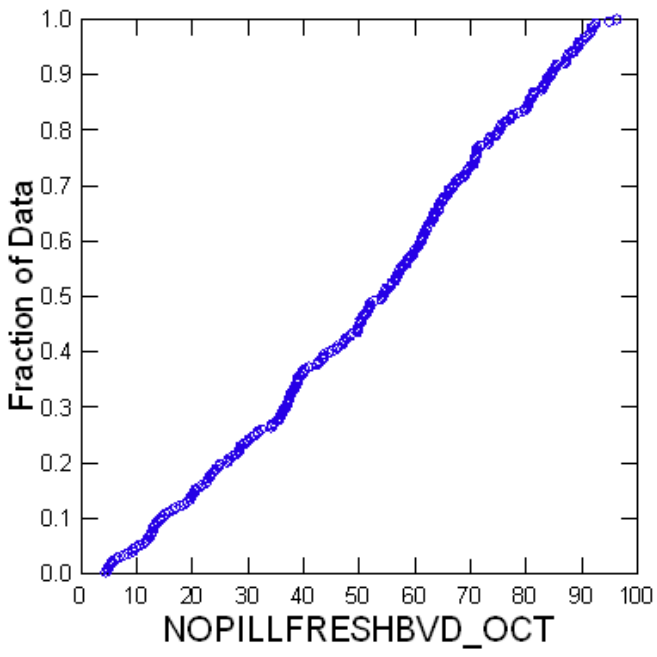

Figure 4: Values of milk anti-p80 BVD Ab binding \% plotted against total fraction of all cows accounted for as values increased (Ab in milk of cows is inversely related; higher \%'s indicate less Ab in cows' milk). The 11 cows in the upper right corner are the 11 cows with Ab binding $\%>90 \%$, indicating possible Persistently Infected BVD status or vaccine failures. Values shown are for October Ab binding \% in fresh milk with no Bronopol preservative pill.

milk was $40 \mathrm{~kg}$, with 305 day age, and season and fat corrected mature equivalent (305ME) projected milk production of 11,604 kg. For all 15 cows at the time $>90 \%$ BVD\%, means were 107 DIM (range $41-188$ DIM), daily milk $44 \mathrm{~kg}, 305 \mathrm{ME} 12,896 \mathrm{~kg}$. All cows tested during either month with valid DHIA milk production data (those not too fresh to test or with missing milk weights; $\mathrm{n}=496$ ) had mean $305 \mathrm{ME} 13,450 \mathrm{~kg}$. BVD antigen capture ELISA using ear notch testing was negative for PI status from all 345 cows tested, including all 279 cows whose milk was also tested.

General linear models were used to determine which cow characteristics might be significantly associated with BVD\% and 305ME milk production (outcome variables). Three outliers were 
Citation: Wilson DJ, Rood KA, Goodell GM (2012) Bovine Viral Diarrhea Milk ELISA Test Detecting Anti-p80 Antibody - Association with Milk Handling Methods and Cow Characteristics. J Veterinar Sci Technol 3:114. doi:10.4172/2157-7579.1000114

found in the 305ME model, and while they did not change results, outliers were nevertheless excluded.

The final GLM for BVD\% included stage of lactation as defined by ranges of DIM (1-9, 10-30, 31-60, 61-150, 151-300, 301-360, $>360$ DIM) and daily milk production on test day. The model only moderately explained variation among cows in BVD\% $\left(\mathrm{R}^{2}=0.23\right)$, but was significant $(\mathrm{P}<0.001)$. The BVD\% means for cows within some ranges of DIM were significantly different from each other as follows: 1-9 DIM (15.7\%) and 10-30 DIM (33.9\%) were different from each other but were both lower than for all other stages of lactation, 61-150 DIM $(60.0 \%)$ was higher than for every other stage of lactation $(\mathrm{P}<$ 0.05, ANOVA, Tukey's) (Table 1 and Figure 5). This indicates that anti-BVD Ab in cows' milk was relatively high for the first month after calving, and decreased to relatively low $\mathrm{Ab}$ at mid-lactation. The GLM also detected a significant but numerically small negative association between daily milk production and anti-BVD Ab in milk.

Indeed, in the 15 cows found with $>90 \%$ BVD\% (low anti-BVD $A b)$, the effect of increasing stage of lactation indicated by the GLM is partially evident. Eleven of the 15 low anti-BVD Ab cows were found during the second month of the study; 10 had been tested the previous month and none had $>90 \%$ BVD\% then. Their mean DIM increased from 91 to 119 days, and their median DIM increased from 74 to 88 days. However, all 4 cows with low anti-BVD Ab during the first month were re-tested and none repeated with $>90 \%$ BVD\% during the second month, increasing in anti-BVD Ab while their mean DIM increased from 116 to 151 days, and their median DIM increased from 108 to 143 days.

The final GLM for 305ME projected milk production included DIM, lactation number, daily milk production on test day, and BVD\%. The model explained much of the variation among cows in $305 \mathrm{ME}\left(\mathrm{R}^{2}=\right.$

Table 1: Mean milk anti-p80 BVD Ab binding \% from fresh milk samples with no Bronopol preservative pill for 491 cows in different stages of lactation (ranges of days in milk).

BVD\% binding means by ranges of days in milk

\begin{tabular}{|l|c|c|c|}
\hline DIM Range & BVD\% & $n$ & Standard deviation \\
\hline $1-9$ & $15.7^{\mathrm{a}}$ & 8 & 13.4 \\
\hline $10-30$ & $33.9^{\mathrm{b}}$ & 34 & 21.0 \\
\hline $31-60$ & $46.4^{\mathrm{d}}$ & 53 & 22.9 \\
\hline $61-150$ & $60.0^{\mathrm{c}}$ & 149 & 21.2 \\
\hline $151-300$ & $47.4^{\mathrm{d}}$ & 185 & 21.2 \\
\hline $301-360$ & $40.5^{\mathrm{d}}$ & 37 & 23.5 \\
\hline$>360$ & $46.1^{\mathrm{d}}$ & 25 & 24.8 \\
\hline
\end{tabular}

Means with the same superscript letter are not significantly different from each other, $\alpha=0.05$, ANOVA, Tukey's.

Table 2: General linear model for cow characteristics associated with 305 day projected milk production $(\mathrm{kg})$ corrected for age, season and fat.

\begin{tabular}{|l|l|l|l|l|}
\hline Parameter & Estimate* & Standard Error & $\mathrm{t}$ Value & $\mathrm{Pr}>\mathrm{t}$ \\
\hline Intercept & 5677 & 424.0 & 13.4 & $<0.001$ \\
\hline Days in milk & 10 & 0.9 & 11.9 & $<0.001$ \\
\hline $\begin{array}{l}\text { Lactation } \\
\text { number }\end{array}$ & -554 & 82.6 & -6.7 & $<0.001$ \\
\hline Daily Milk $\dagger$ & 82 & 3.5 & 23.9 & $<0.001$ \\
\hline BVD\% & -12 & 4.4 & -2.8 & 0.005 \\
\hline
\end{tabular}

* Estimated effects on 305 day milk production shown in $\mathrm{kg}$

$\dagger$ Effect of each $0.45 \mathrm{~kg}$ increase in daily milk production at the time of DHIA test

$\ddagger$ effect of each one percent increase in anti-p80 BVD Ab binding \% (increased

binding indicates less anti-p80 BVD Ab in cow's milk)

$\mathrm{R}^{2}=0.72, \mathrm{P}<0.0001$

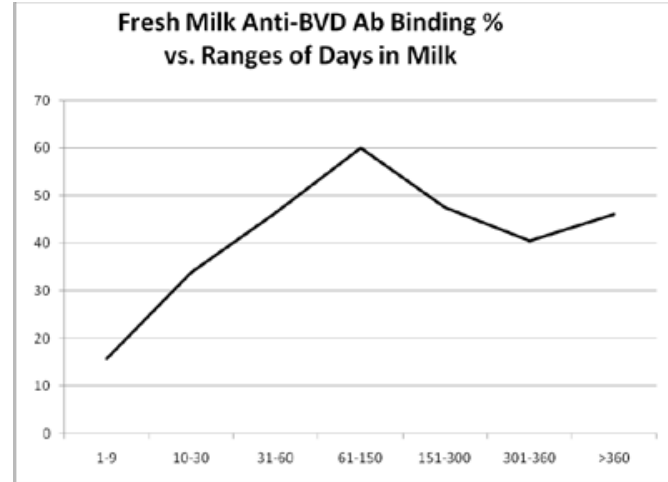

Figure 5: Mean milk anti-p80 BVD Ab binding \% from fresh milk samples with no Bronopol preservative pill for cows in different stages of lactation (ranges of days in milk).

0.72), and was highly significant $(\mathrm{P}<0.0001)$ (Table 2$)$. Increased DIM, higher milk production on test day and younger cows - particularly those in $1^{\text {st }}$ and $2^{\text {nd }}$ lactation - were associated with higher 305ME milk. When ranges of DIM or attempts to characterize the lactation curve were fitted into the model, they were of less explanatory value than DIM as a continuous variable. Similarly, when lactation number was converted to categorical variables such as $1^{\text {st }}$ and $2^{\text {nd }}$ lactation vs. $3^{\text {rd }}$ plus lactation, it was of less explanatory value than simply using cows' actual number of lactations as a categorical ordinal value. Adjusting for the above factors, increased BVD\% (decreased anti-BVD Ab in milk) was significantly associated with decreased milk production. Each onepercent increase in BVD\% was associated with 12 fewer kg of milk per lactation; e.g. if one cow had 50\% more BVD\% (less anti-BVD Ab) than another, she would be expected to produce $600 \mathrm{~kg}$ less $305 \mathrm{ME}$ milk adjusting for the other significant factors.

\section{Discussion}

The range of milk ELISA values of BVD\% observed comprised nearly the entire range of possible values from 0 to $100 \%$, and they were normally distributed. While BVD\% values appeared similar among methods of handling milk samples - fresh, preservative pilled, refrigerated or frozen - they did differ statistically between 2 of the methods. Values were also moderately correlated in the same cow across the 2 consecutive monthly tests. The only type of milk sample which detected any cows with $>90 \%$ BVD\% (low anti-BVD Ab) was fresh milk with no preservative. This might seem to indicate that cows' milk anti-BVD Ab was increased as milk samples degenerated (pilled or frozen), which is not logical. What more likely occurred was that nonspecific binding to the p 80 antigen-coated test wells, thus inhibiting more of the secondary test kit $\mathrm{Ab}$ binding, was increased in the less fresh and/or preserved milk samples [10].

Anti-BVD Ab in cows' milk was relatively high for the first month after calving, and decreased to relatively low levels by mid-lactation. As time since BVD vaccination - administered at dry off and 15-21 DIM increased as lactation progressed, antibody against $\mathrm{p} 80$ antigen of BVD decreased. This agrees with a previous report that antibody, which has been characterized as important to protection against BVD, wanes as time passes following vaccination, and that booster immunizations are important to maintaining immunity against BVD in cattle [11]. When adjusted for age, stage of lactation and milk production on the day of testing, cows with higher anti-BVD Ab milked better than those with lower Ab. The association of individual cow BVD Ab with 
Citation: Wilson DJ, Rood KA, Goodell GM (2012) Bovine Viral Diarrhea Milk ELISA Test Detecting Anti-p80 Antibody - Association with Milk Handling Methods and Cow Characteristics. J Veterinar Sci Technol 3:114. doi:10.4172/2157-7579.1000114

milk production, especially in non-PI cows, has not been reported previously.

Milk ELISA results for BVD did not consistently identify any cows as PI or possible vaccine failures, because while approximately $5 \%$ of the cows were detected with $>90 \%$ BVD\% (low anti-BVD Ab), none of the cows repeated as low anti-BVD Ab animals on another monthly DHIA test. Most of the low anti-BVD Ab cows were detected during the second monthly test, as they progressed from about the $3^{\text {rd }}$ to $4^{\text {th }}$ month of lactation, which might be expected with waning antibody as time passed since vaccination. However, this does not explain why all cows with $>90 \%$ BVD\% during the first month did not persist into the second month, instead re-testing with higher anti-BVD Ab as they progressed from about the $4^{\text {th }}$ to $5^{\text {th }}$ month of lactation.

The detection and elimination of all PI animals does not guarantee BVD-free status in dairy herds even if they are completely closed to purchased animals. The view that closed herds "cannot develop BVD infections" is being reevaluated. Some countries with national BVD control programs and excellent records have found that approximately $10 \%$ of herds that have been certified free of BVD based on testing of all calves born "relapse" (i.e. new BVD-positive animals are discovered) each year even if the herds are isolated from other animals [2]. There are several known mechanisms for how this can happen. In fecal material, BVD virus has been shown to survive for at least 3 weeks. Documented spread of BVD virus has occurred by flies, nose tongs, and contaminated rubber stoppers on vials of vaccine (rubber stoppers were allowed to dry and looked visibly clean), occupation of a pen previously occupied by a PI calf for up to 1 day after its removal, and by ambient air over a distance of $10 \mathrm{~m} \mathrm{[12].}$

Nevertheless, detection and removal of all PI animals remains the single BVD control measure with the most demonstrated effectiveness at reducing or eliminating the disease from dairy herds [2,9]. In the present study, the finding of no PI cows by the milk ELISA test agreed with the results of the antigen capture ear notch ELISA performed concurrently, but the lack of repeatability from month to month in the status of cows identified as PI or vaccine failure suspects as described above suggests a limitation of the practical application of the milk ELISA test. Another limitation of the milk test is that animals could not be tested until they are approximately 2 years old, when they first become lactating cows.

Where the milk BVD test might be most beneficial to the dairy industry would be as a practical and convenient test for screening herd replacements, especially when large numbers of lactating cows are purchased and mixed into different production groups throughout a dairy herd. Further study, including testing of cows diagnosed as BVD PI according to the antigen capture ear notch ELISA, is needed to evaluate this BVD ELISA test.

\section{Acknowledgements}

The authors thank the ownership and staff of the cooperating dairy farm, Rocky Mountain DHIA, Idexx Laboratories, and the staff at the Utah Veterinary Diagnostic Laboratory, AgSource Laboratories and The Dairy Authority.

\section{References}

1. Lambert G, Fernelius AL (1968) Bovine viral diarrhea virus and Escherichia coli in neonatal calf enteritis. Can J Comp Med 32: 440-446.

2. Laureyns J, Ribbens S, de Kruif A (2010) Control of bovine virus diarrhoea at the herd level: reducing the risk of false negatives in the detection of persistently infected cattle. Vet J 184: 21-26.

3. Roeder PL, Harkness JW (1986) BVD virus infection: prospects for control. Vet Rec 118: 143-147.

4. Peterhans E, Bachofen C, Stalder H, Schweizer M (2010) Cytopathic bovine viral diarrhea viruses (BVDV): emerging pestiviruses doomed to extinction. Vet Res 41: 44.

5. Straver PJ, Journée DL, Binkhorst GJ (1983) Neurological disorders, virus persistence and hypomyelination in calves due to intra-uterine infections with bovine virus diarrhoea virus. II. Virology and epizootiology. Vet Q 5: 156-164.

6. Bolin SR, McClurkin AW, Coria MF (1985) Frequency of persistent bovine vira diarrhea virus infection in selected cattle herds. Am J Vet Res 46: 2385-2387.

7. Sandvik T (2005) Selection and use of laboratory diagnostic assays in BVD control programmes. Prev Vet Med 72: 3-16.

8. Driskell EA, Ridpath JF (2006) A survey of bovine viral diarrhea virus testing in diagnostic laboratories in the United States from 2004 to 2005. J Vet Diag Invest 18: 600-605.

9. Gripshover EM, Givens MD, Ridpath JF, Brock KV, Whitley EM et al (2007) Variation in $E(r n s)$ viral glycoprotein associated with failure of immunohistochemistry and commercial antigen capture ELISA to detect a field strain of bovine viral diarrhea virus. Vet Microbiol 125: 11-21.

10. Willingham MC (1999) Conditional epitopes: is your antibody always specific? J Histochem Cytochem 47: 1233-1236.

11. Alvarez M, Donate J, Makoschey B (2011) Antibody responses against nonstructural protein 3 of bovine viral diarrhoea virus in milk and serum samples from animals immunised with an inactivated vaccine. Vet J 191: 371-376.

12. Niskanen R, Lindberg A (2003) Transmission of bovine viral diarrhoea virus by unhygienic vaccination procedures, ambient air, and from contaminated pens. Vet J 165: 125-130. 